\title{
"FUNCTIONAL FOOD AWARENESS IN RELATION TO LIFESTYLE CHANGES IN OBESE WOMEN OF BHOPAL."
}

KEY WORDS: Functional

foods, Awareness

Zabi Faraz Khan*

PhD research scholar Sarojini Naidu Govt. Girls P.G. (Auto.) College, Barkatullah University Bhopal [M.P.]. *Corresponding Author

\section{Dr. Nilima Varma Director Madhya Pradesh State Institute of Hospitality,Travel and Tourism.}

"Let food be thy medicine and medicine be thy food," as said by Hippocrates nearly 2,500 years ago, is receiving renewed interest in the health enhancing role of specific foods or physiologically-active food components, so-called functional foods (Hasler, 1998). The urbanization has a strong adverse effect on the dietary pattern in old age women who are lacking awareness about functional food. The awareness on functional foods is very use full in old age women who have clinical diseases. Thus, the current study is targeted on educating old age women which will have an effect on food habit for better health. The teaching aid used in the awareness is a colorful leaflet. The awareness on functional foods among women educated were evaluated through questionnaire before and after the leaflet distribution and the results

E. were statistically analyzed.

Context: To promote better health and to help reduce the risk of diseases through the emerging fields of functional foods and nutraceuticals as a concept of nutrition, this originated in Japan. To emphasis on the Hippocrates saying, "Let food be your medicine and medicine be your food".

The purpose of this study was to aware people regarding consumption of functional food to improve their lifestyle. To identify the need for information related to functional foods among older women (40-60 years old) and to assess awareness and perceptions of health claims on self-made functional food.

Study Design: The Pre-test and post-test study was planned to evaluate the awareness of functional foods among old age women who were suffering with clinical diseases in Bhopal city of Madhya Pradesh.

Results: The mean scores obtained by the selected women on the awareness on functional foods before and after leaflet demonstration was found significant in Pair $\mathrm{t}$-test.

Conclusions: The attempt to distribute a leaflet was observed to be a beneficial tool in inculcating awareness since majority of the participants changed their dietary pattern as they have changed their routine breakfast.

\section{INTRODUCTION}

"There is no real excellent in all this world. which can be separated from right living:" David Star Jordan "Let food be thy medicine and medicine be thy food," as said by Hippocrates nearly 2,500 years ago, is receiving renewed interest in the health enhancing role of specific foods or physiologically-active food components, so-called functional foods (Hasler, 1998). Clearly, all foods are functional, as they provide taste, aroma, or nutritive value.Within the last decade, however, the term functional as it applies to food has adopted a different connotation -- that of providing an additional physiological benefit The term functional foods were first introduced in Japan in the mid-1980s and refers to processed foods containing ingredients that aid specific bodily functions in addition to being nutritious Functional food is a modified food that claims to improve health or well-being by providing benefit beyond that of the traditional nutrients it contains. in a way that is relevant to either an improved state of health and well-being and/or reduction of risk of disease. It is consumed as part of a normal food pattern.

Health-conscious consumers are increasingly seeking functional foods in an effort to control their own health and well-being. The field of functional foods, however, is in its infancy. Claims about health benefits of functional foods must be based on sound scientific criteria (Clydesdale, 1997).

Vella, M. N. et al. (2014) had studied that; provides insight into the current and preferred sources of information for functional foods, as well as the awareness, perceptions and understanding of health claims on functional foods among the older adult consumer segment. Among participants, an increased awareness and knowledge pertaining to functional foods was the most frequently reported factor that would increase consumption and the majority of participants indicated that they actively seek out information about functional foods, suggesting that older adults are motivated to expand their knowledge and understanding of functional food products. The food label was also identified as a primary source of information pertaining to functional foods; however, older adults in the current study perceived the need for more information, specifically with regards to the health benefits of functional foods.

In the past, studies have established that the awareness about functional foods plays a vital role in their choice and acceptance of functional food. (R.W.Naylor et al., 2009) and (R. Raghunathan et al.,2006).

Lifestyle is the typical way of life of an individual, group, or culture. The term was originally used by Austrian psychologist Alfred Adler (1870-1937). The term was introduced in the 1950s as a derivative of that of style in modernist art. The term refers to a combination of determining intangible or tangible factors. Tangible factors relate specifically to demographic variables, i.e., an individual's demographic profile, whereas Intangible factors concern the psychological aspects of an individual such as personal values, preferences, and outlooks. An individual's health depends a lot on their lifestyle. Maintaining physical and mental health is crucial to an individual's longevity. For many people, abnormal cholesterol levels are partly due to an unhealthy lifestyle. This often includes eating a diet that is high in fat. Other lifestyle factors are: being overweight, or 1 ack of exercise Some health conditions can also lead to abnormal cholesterol, including:

- Diabetes

- Kidney disease

- Polycystic ovary syndrome

- Pregnancy and other conditions that increase levels of female hormones

- Underactive thyroid gland.

The Gram (Cicer arietinum) is a legume of the family Fabaceae, subfamily Faboideae, these seeds are high in protein. A high-fiber diet lowers your cholesterol levels and helps prevent constipation. Fiber helps regulate blood-sugar levels in individuals with diabetes. 
Soybean Soy has been in the spotlight during the 1990s. Not only is soy a high-quality protein, as assessed by the FDA's "Protein Digestibility Corrected Amino Acid Score" method, it is now thought to play preventive and therapeutic roles in cardiovascular disease (CVD), cancer, osteoporosis, and the alleviation of menopausal symptoms.

Barley is a wonderfully versatile cereal grain with a rich nutlike flavor and an appealing chewy, pasta-like consistency. The relationship between diet, health and Life style as grown it is essential to know about the importance of a healthy life style, including diet and its role in reducing our risk of illness and disease. This knowledge has allowed easier access to a safer, more varied diet, all of which should ensure longevity. Increased affluence and urbanization are also linked to a lifestyle where our daily routine requires less physical activity. We now have a real challenge to balance energy intake and expenditure as more of us are becoming overweight. Functional Food (Barely, Soya, Gram whole grain) diet is a need of today healthy and fit life.

\section{OBJECTIVES}

The purpose of this study is to aware people regarding consumption of functional food to improve their lifestyle. The following major research objectives were addressed in the present study.

Objl. To identify obese women from different hospitals of Bhopal city.

Obj2. To develop tools for the awareness program for obese women.

Obj3. To educate obese women about the benefits of functional food with the help of IEC tools to improve their life style.

\section{Hypothesis:}

Hl. There will be significant change happen in Obese women after educating them about functional food through awareness tool so that they are able to maintain their lifestyle accordingly.

\section{REVIEW OF LITERATURE}

Food in adition to its physiological effect has psychological, organoleptic and healing properties.

Bridging the gap between food and medicine Hippocrates highlighted around 2000year ago "Let food be your medicine and medicine be your food" (Rishi RK,2006). 'Functional Food' is not a new concept but it became more important recently due to the collapse of most social health system because 'Functional Foods' allow low-cost prevention of numerous diseases.

Functional foods can be defined as those providing health benefits beyond basic nutrition and include whole, fortified, enriched or enhanced foods which have a potentially beneficial effect on health when consumed as part of a varied diet on a regular basis at effective levels.

Functional food enters the concept of considering food not only necessary for living but also as a source of mental and physical well-being, contributing to the prevention and reduction of risk factors for several diseases or enhancing certain physiological functions (López-Varela S,2002). The beneficial effects could be either maintenance or promotion of a state of well-being or health and/or a reduction of risk of a pathologic process or a disease (Roberfroid MB, 1999).

Functional food: a concept rather than a product the recently released European consensus publication proposes (Diplock et al., 1999) A working definition: "A food can be regarded as 'functional' if it is satisfactorily demonstrated to affect beneficially one or more target functions in the body, beyond adequate nutritional effects, in a way which is relevant to either the state of well-being and health or the reduction of the risk of a disease". The beneficial effects could be either maintenance or promotion of a state of well-being or health and/or a reduction of the risk of a pathologic process or a disease.

P.Jeyasekaran (2015) was also conduct a study on "Awareness on functional foods and nutraceuticals among educated home makers through booklet distribution."

McConnon A, et.al, (2004) was study and found that, as concepts in nutrition move towards emphasizing the use of foods to promote better health and to help reduce the risk of disease, new concept of functional food has emerged.

\section{METHODOLOGY}

The Methodology used for the study was random sampling method done for hundred women belonging to age group between $40-60$ years.

Sampling Method: - Purposive random sampling. Sampling size: - Present study done by using a sample of 100 obese women age group of 40-60Years.

Sampling area: - Hospitals from old and new Bhopal. Study Design: -Using a Randomize match pretest-posttest control group design, present study using a sample of 50 women in experimental group and 50 in control group.

Awareness Tool -The teaching aid used in the awareness programme was a colourful leaflet fabricated by the researcher which consists of basic information on functional foods and method of preparation: functional foods, their sources, health benefits and recommended dietary allowance also followed by some cooking recipe was issued. Tool for Data collection- A questionnaire containing sections like personal information, clinical history and life style related questions were using to assess the awareness, knowledge and current state.

Procedure of Data collection - Participants were individually contacted and consent was obtained for participation. Pretest and post test data was taken. Ample time was given to them to completely go through the leaflet and the same questionnaire was being filled by them after intervention. The filled questionnaires were collected and analysed. Statistical Analysis Used: The data were analysed paired ' $t$ ' test and the results were interpreted and discussed. This study was focused on the role of awareness about functional food diet in the obesity reduction and life style among 40 plus obese women.

Specific and General information/Variables

Dependent variables: Awareness about functional food and life style questionnaire.

Independent variables: Awareness tool about Functional Food (Barely, Soya, Gram whole grain $30 \mathrm{~g}$ whole grain).
External
tion:
1. Age-Postmenopausal women 45-60
2. Sex-Female
3. Socioeconomic status-Middle class
4. Physical activity-Housewife
5. Exercise-Daily $1 \mathrm{~km}$ morning walk
6. Food habit-Veg $\&$ Non-Veg
7. Disease status-Not severely ill
8. Marital status-Married
9. Status-Urban and semiurban
10. FamilyType-Joint 


\section{Habit of substance and alcohol abuse -nil}

\section{Feed-Back}

Pretest and post-test data were collected on a selected variable with help of a questionnaire in the face-to-face interview, after the completion of data collection participants were thanked for their participation.

\section{Limitations}

Expected result was achieved in controlled situation because all external situational variables are controlled by selection.

Ll.This study is only done on women (Age of 40-60) below and above 60 are excluded

L2. This study is not conducted on children, old age person and obese male.

L3. This study is done on only obese women from OPD from hospitals of Bhopal.

\section{RESULTS AND DISCUSSION}

In the present study, a sample of 50 women was used in experimental group. External variable- were matched \& controlled by selection:

Age -Postmenopausal women 45-60, Sex -Female, Socioeconomic status -Middle class, Physical activity Housewife, Exercise -Daily $1 \mathrm{~km}$ morning walk, Food habit Veg \& Non-Veg, Disease status -Not severely ill, Marital status -Married, Status -Urban and semiurban, Family Type-Joint, Habit of substance and alcohol abuse -nil

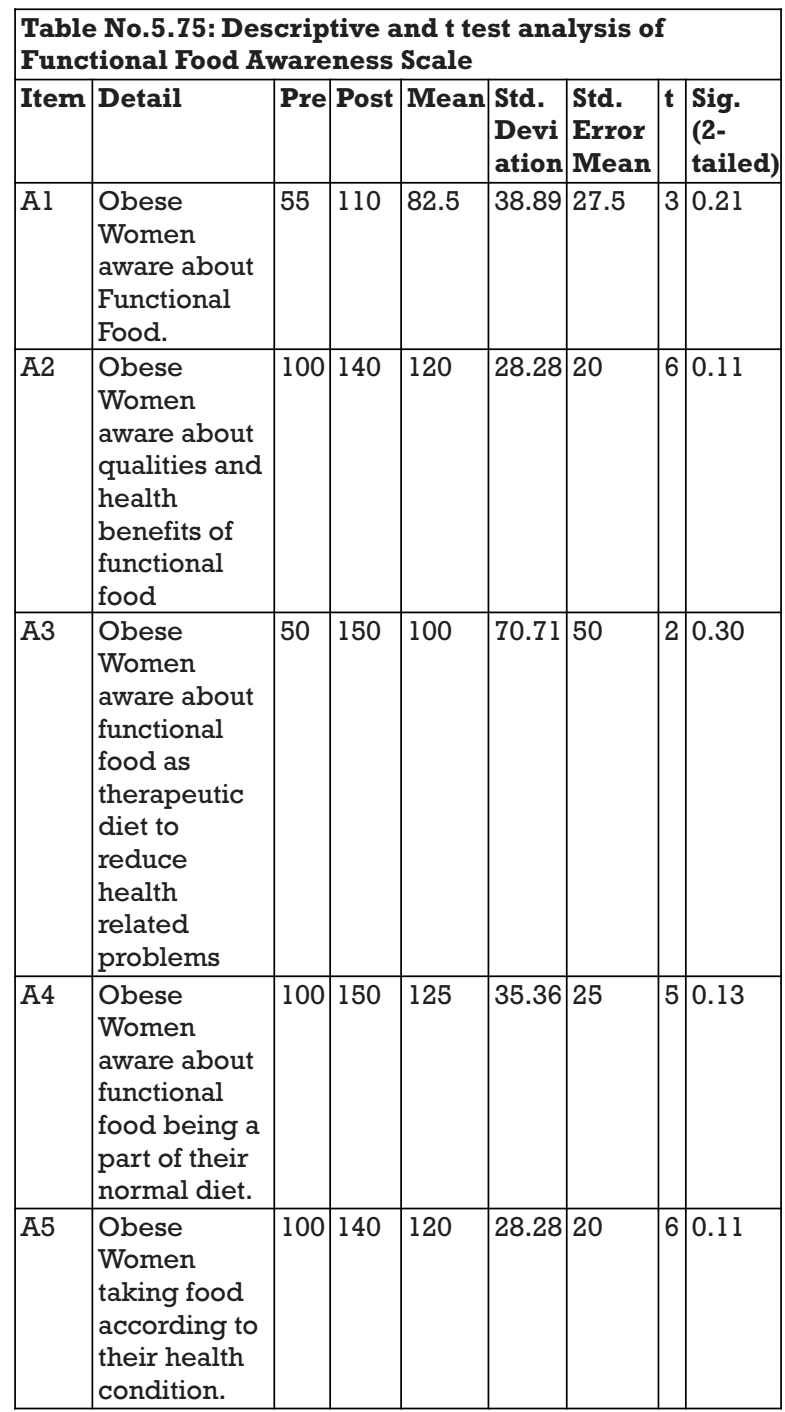

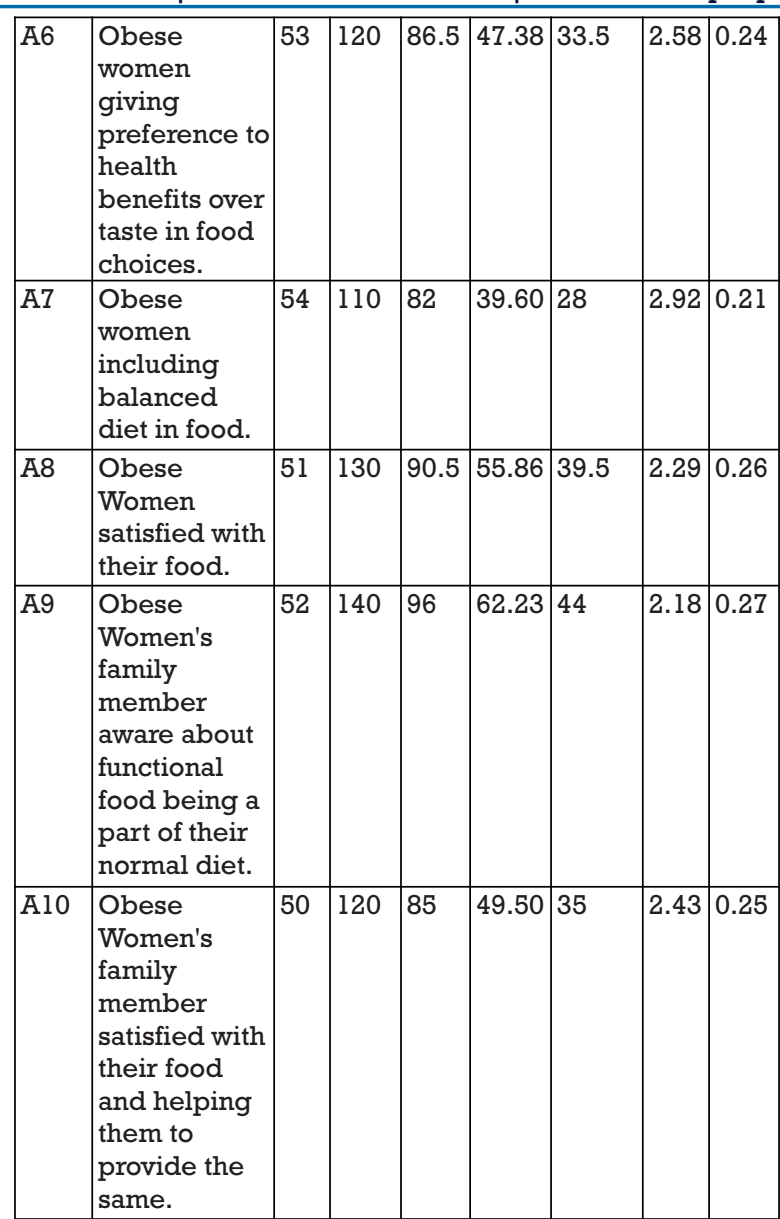

From the results, we can say that: Educating them about functional food through awareness tools before intervention \& after intervention scores were Significant, at $\mathrm{p}<0.05$ level.

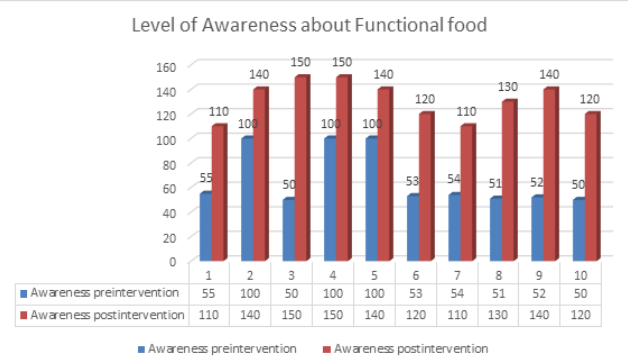

Fig 5.56: Dietary Awareness score of Obese women before and after Intervention.

There will be significant change happen in Obese women after educating them about functional food through awareness tools so that they are able to maintain their lifestyle accordingly.

\section{Paired Samples Test}

Table No.5.76: Paired Sample Statistics for Dietary Awareness.

\begin{tabular}{|c|c|c|c|c|c|c|c|c|}
\hline \multicolumn{6}{|c|}{ Paired Samples Test } & & & \\
\hline \multicolumn{6}{|c|}{ Paired Differences } & \multirow[t]{2}{*}{$\mathbf{t}$} & df & Sig. (2- \\
\hline \multirow[t]{2}{*}{$\begin{array}{c}\text { Mea } \\
\text { n }\end{array}$} & \multirow[t]{2}{*}{$\begin{array}{c}\text { Std. } \\
\text { Devi } \\
\text { ation }\end{array}$} & \multirow[t]{2}{*}{$\begin{array}{c}\text { Std. } \\
\text { Error } \\
\text { Mean }\end{array}$} & \multicolumn{3}{|c|}{\begin{tabular}{|c|}
$95 \%$ \\
Confidenc \\
e Interval \\
of the \\
Difference \\
\end{tabular}} & & & tailed) \\
\hline & & & \begin{tabular}{|l} 
Lov \\
er
\end{tabular} & & & & & \\
\hline
\end{tabular}




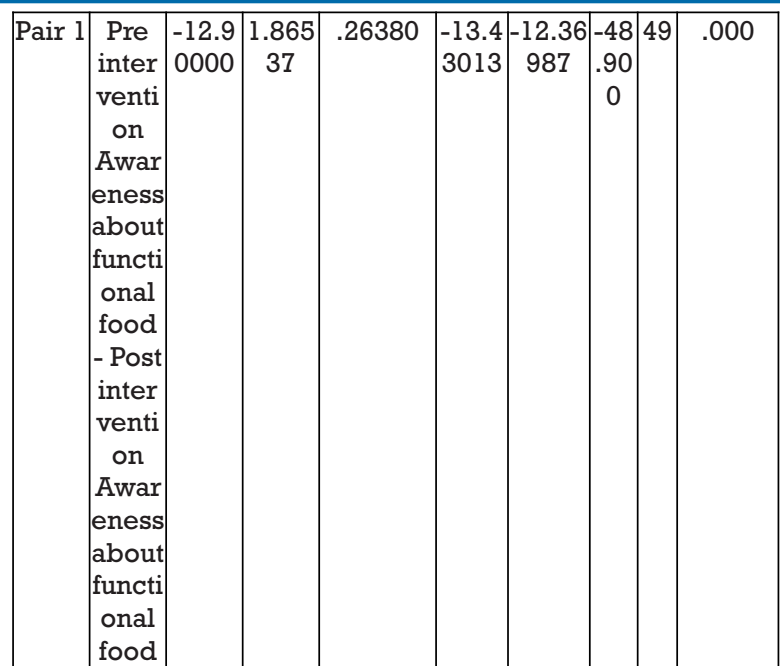

There was a significant average difference between before intervention \& after intervention scores in experimental group feducating them about functional food through awareness tools $(\mathrm{t} 49=48.9, \mathrm{p}<0.05)$.

On average, after intervention scores were 12 points higher than before intervention scores (95\% CI [-13.43,-12.36]).

Identification of obese women from different hospitals of Bhopal city was done effectively.

The tool was developed for the awareness program for obese women.

Obese women were educated about the benefits of functional food with the help of IEC tools to improve their lifestyle.

\section{Level of Awareness about Functional Food}

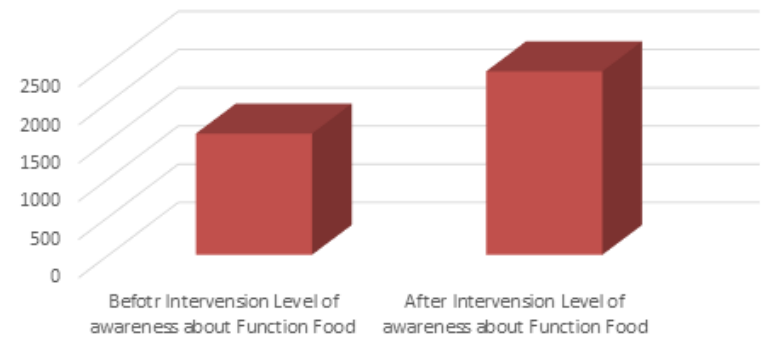

Fig No.5.57: Level of Awareness about Functional Food before and after intervention

The study Hypothesis found correct: There will be significant change happen in Obese women after educating them about functional food through awareness tools so that they are able to maintain their lifestyle

"These results suggest that educating them about functional food through awareness tools really does have an effect on life style. Specifically, our results suggest that Obese women after educating them about functional food through awareness tools they are able to maintain their lifestyle accordingly."

The attempt to distribute a leaflet was observed to be a beneficial tool in inculcating awareness since majority of the participants changed their dietary pattern as they have changed their routine breakfast. After awareness they have started to include recommended functional food each day. So, it is the need of the apt time for the functional foods to be incorporated in the diets of everyone in the family. P.Jeyasekaran (2015) and Mc Connon A, et.al, (2004) was also conduct a study on "Awareness on functional foods and nutraceuticals among educated home makers through booklet distribution."

|www.worldwidejournals.com
Thus, more of awareness programs on significance of functional foods should be organized by the nutritionist targeting on women for revolution.

\section{CONCLUSIONS}

We meet all three objectives of the research and hypothesis found true; Identification of obese women from different hospitals of Bhopal city was done effectively.

The tool was developed for the awareness program for obese women.

Obese women were educated about the benefits of functional food with the help of IEC tools to improve their lifestyle.

Study Hypothesis: There will be significant change happen in Obese women after educating them about functional food through awareness tools so that they are able to maintain their lifestyle accordingly was found significant.

Functional food consumption increases after awareness.

- lifestyle changed significantly after consuming functional food.

- Functional food was easy to cook and ready to eat.

- Functional food is also easy to chew in women who have teeth problems.

- Easy to digest, comparatively cheaper with other food, and full of Nutrition's.

- Functional food Barley, Gram, and Soyabean acceptable and easily available in our society.

- After eating functional food women feel active, energetic, and full of life.

- Functional food is very useful and beneficial in our society, especially in older women.

\section{REFERENCES}

1. Clydesdale, F.M. 1997. A proposal for the establishment of scientific criteria for health claims for functional foods. Nutr. Rev. 55 (12): 413-422

2. Diplock A. T., Aggett P. J., Ashwell M., Bornet F., Fern E. B. and Roberfroid M. B. (1999). Scientific concepts of functional foods in Europe: Consensus Document. British Journal of Nutrition 81 (Suppl. 1), S1 \pm S27.

3. Hasler, C.M. 1998. A new look at an ancient concept. Chem. Industry Feb. 2:8489.

4. Jeyasekaran P. Awareness on functional foods and nutraceuticals among educated home makers through booklet distribution. J Med Nutr Nutraceut [serial online] 2015 [cited 2020 Nov 1]; 4:39-46. Available from: https://www.jmnn.org/text.asp?2015/4/1/39/146160

5. McConnon A, Fletcher PL, Cade J, Greenwood DC, Pearman AD. Differences in perceptions of functional foods: UK public vs. nutritionists. Nutr Bull 2004; 29:11-8.

6. Rishi RK. (2006) Nutraceutical: borderline between food and drug. Pharma Review. Retrieved 03 Dec 2013 from http://www.kppub.com/articles/herbalsafety-pharmareview-004/nutraceuticals-borderline-between-foodanddrugs.

7. Roberfroid MB. What is beneficial for health? The concept of functional food. Food Chem Toxicol. 1999;37:1034-41. [PubMed]

8. R. Raghunathan, R.W. Naylor, and W. D. Hoyer, "The unhealthy = tasty intuition and its effects on taste inferences, enjoyment, and choice of food products," Journal of Marketing, vol. 70, no. 4, pp. 170-184, 2006.View at: Publisher Site | Google Scholar

9. R. W. Naylor, C. M. Droms, and K. L. Haws, "Eating with apurpose: consumer response to functional food health claimsin conflicting versus complementary information environments," Journal of Public Policy \& Marketing, vol.28, no.2,pp.22 1-233,2009.View at: Google Scholar

10. Vella, M. N., Stratton, L. M., Sheeshka, J., \& Duncan, A. M. (2014). Functional food awareness and perceptions in relation to information sources in older adults.Nutrition journal, 13,44.https://doi.org/10.1 186/1475-2891-13-44 